\title{
Aquisição da fonologia do português brasileiro: evidências da fala infantil
}

\author{
Livia Rodrigues CORDEIRO (1) \\ Universidade Federal do Rio de Janeiro (UFRJ) \\ Danielle Kely GOMES (1) \\ Universidade Federal do Rio de Janeiro (UFRJ)
}

\section{RESUMO}

A conferência intitulada Adquirindo a Fonologia do Português brasileiro, proferida pela Prof. ${ }^{a}$, Dr. ${ }^{a}$ Raquel Santana Santos (USP), busca apresentar questões acerca da aquisição de propriedades fonológicas do Português brasileiro, através de pesquisas realizadas pela conferencista e em cooperação com outros investigadores. Para tanto, utilizam-se dados do Português brasileiro para descrever como as unidades, as estruturas, as regras, as propriedades prosódicas e os processos são adquiridos pelas crianças, de modo a explicar como funciona o sistema fonológico em aquisição. Busca-se discutir como se configura a aquisição das regras de acento primário, de ditongação/elisão em fronteira vocabular e vozeamento de consoantes fricativas em coda.

\section{ABSTRACT}

The conference entitled Acquiring the Brazilian Portuguese Phonology, given by Raquel Santana Santos, $\mathrm{PhD}$ (USP), seeks to present questions about the acquisition of phonological properties of Brazilian Portuguese, through research conducted by the speaker and in cooperation with other researchers. To this end, the presenter uses data from Brazilian Portuguese to describe how the units, structures, rules, prosodic properties and processes are acquired by children, in order to explain how the phonological system in acquisition works. The aim is to discuss how the acquisition of primary stress rules, diphthongation/elision in vocabular border and fricative consonants in coda are configured. 


\section{REVISTA DA ABRALIN}

PALAVRAS-CHAVE

Aquisição Fonológica. Português brasileiro. Regras e processos.

\section{KEYWORDS}

Phonological acquisition. Brazilian Portuguese. Rules and processes.

A Prof. ${ }^{a}$, Dr. $^{a}$ Raquel Santana Santos propôs-se a discutir como se processa a aquisição do sistema fonológico do Português brasileiro como L1 por crianças, com base na abordagem dos processos de a) aquisição do acento primário; b) interferência dos parâmetros acentuais da L1 na aquisição do acento em L2; c) aquisição das regras de ditongação e de elisão; d) aquisição da regra de vozeamento das consoantes fricativas em coda; e) interferência de regra de vozeamento de L1 na aquisição de L2.

O primeiro fenômeno apresentado é a aquisição do acento primário no português brasileiro. É importante destacar que o tratamento dado à aquisição do acento é pautado na Teoria de Princípios e Parâmetros (CHOMSKY, 1965; 1981). Ao questionar como os parâmetros se estruturam na Gramática Universal, faz-se alusão às propostas de Dresher e Kaye (1990) e Fikkert (1994), que advogam pela existência de um valor default, não marcado, para a aquisição do acento primário. Nos trabalhos citados, defende-se que, no parâmetro do núcleo, os pés são fortes à esquerda. O diálogo estabelecido entre a pesquisadora e os trabalhos citados é essencial, porque os dados de aquisição do acento primário no português brasileiro parecem não se conformar ao modelo apresentado nas propostas citadas.

Para comprovar que, no português brasileiro, a aquisição da regra de atribuição de acento primário possui propriedades que não se encaixam totalmente na proposta de um parâmetro fixo com proeminência à esquerda, a pesquisadora apoia-se em um estudo experimental, apresentado em Santos e Fikkert (2011). Recolheram-se quatro pares de palavras, em holandês e em português, com dois acentos e duas repetições. O experimento foi realizado por 81 informantes (crianças de 03 e 06 anos de idade e adultos brasileiros). Verificou-se, nessa atividade experimental, se o participante buscava correspondência entre a proeminência e o início da palavra.

Através dos resultados, foi possível perceber que, no holandês, havia uma forte tendência de os informantes acertarem a oposição forte/fraco (troqueus). Crianças de 3 anos acertaram 68\% das vezes, quando a proeminência era à esquerda, mas apresentavam índices mais baixos de acerto quando o pé métrico se estruturava na oposição fraco/forte, num pé iâmbico. Isso indica uma clara preferência por troqueus. No português, não houve um efeito significativo nos acertos.

No entanto, refuta-se a hipótese de que, no português, o parâmetro de acento primário é fixado à esquerda do pé. Com base em Santos (2007), comprova-se que, na aquisição, as crianças produzem formas que contemplam tanto a marcação do acento primário à esquerda quanto à direita do pé. No estágio 1, as crianças produzem monossílabos; no estágio 2, produzem estruturas com a configuração fraco/forte (como, por exemplo "chapéu", produzido como [a'pE]), e não pés com a configuração forte/fraco, como o previsto em outras propostas. Para resolver a questão da marcação paramétrica 


\section{REVISTA DA ABRALIN}

do acento, propõe-se um modelo em que não haja valor inicial para o parâmetro, e sim duas possibilidades: à esquerda ou à direita. Na comparação entre o português e o holandês, os dados revelam que naquele a opção é à direita; neste, à esquerda

No que se refere à interferência do acento da L1 na aquisição de L2, recorre-se aos resultados em Fragozo (2017), Fragozo e Santos (no prelo), estudos que verificam a interferência do acento primário do português na aquisição do inglês como L2. Os experimentos revelam que o maior número de acertos na incidência do acento primário incide nas paroxítonas, em uma correlação direta entre atribuição do acento e o peso da sílaba final. Sílabas finais leves elevaram os índices de acerto da incidência do acento, enquanto em sílabas pesadas, com vogais longas, o índice de acertos foi menor. Essa diminuição no percentual ocorreu porque o PB não apresenta vogais longas. Os resultados revelam que os aprendizes têm adquirido o acento do inglês, já que os estudos demonstram que há um aumento nos índices de acerto na marcação do acento primário na medida em que se avançam os níveis de proficiência na língua estrangeira.

O terceiro fenômeno tratado na apresentação refere-se à aquisição das regras de elisão e ditongação, observadas no âmbito do sândi vocálico externo. O estudo, apresentado em Santos (2007), descreve os processos na produção de três crianças, observadas ao longo de três anos. A autora postula quatro estágios distintos de aquisição das regras.

No estágio I, entre 1;4 a 1;7 anos, as crianças ainda não adquiriram a regra de ditongação/elisão. Todavia, o corpus analisado apresentava apenas 7 contextos de encontro entre duas vogais em palavras distintas, o que limita o potencial explicativo da análise nesse estágio.

No estágio II, entre 1;7 a 2;5 anos, as crianças passam a apresentar muitas ocorrências de elisão de vogais. A elisão incide sobre as vogais com traço [+post], independentemente da ordem em que a vogal apareça na fronteira vocabular; quanto à proeminência da unidade binária, a criança aplica a elisão em proeminências fraca/fraca, fraca/forte, forte/fraca, mas nunca em proeminência forte/forte. A regra de ditongação, no estágio II, é sensível à ordem dos segmentos vocálicos: as crianças realizam a ditongação somente se a segunda vogal é alta, formando ditongos decrescentes, os verdadeiros ditongos em português (consoante Câmara Jr. (1970) e Bisol (1989)).

No estágio III, entre 2;5 a 3;4 anos, observa-se um decréscimo na aplicação das regras de elisão, que atinge a vogal [+ post] ou a $1^{\text {a }}$ vogal, verificada em unidades binárias marcadas pelas proeminências fraca/fraca, fraca/forte, forte/fraca, mas nunca em forte/forte. O estágio III também se caracteriza pela aplicação de regras de ditongação em contextos em que a vogal alta aparece tanto na segunda posição (formando um ditongo decrescente) quanto na primeira posição (tendo como efeito a produção de um ditongo "crescente"). E nesse período, ela adquiriu a estrutura de ditongo crescente (CglV). Por fim, no estágio IV, observa-se que as crianças já aplicam as duas regras em seus devidos contextos.

O último processo apresentado está relacionado à aquisição do vozeamento. Para entender como se processa a aquisição do vozeamento no português, parte-se da proposta de Câmara Jr. (1988) para a representação fonológica das fricativas no contexto de coda. O autor postula que a representação subjacente dessa coda é /s/, porque há mais contextos de realização da fricativa 


\section{REVISTA DA ABRALIN}

alveolar surda, [s]. Valendo-se dos resultados apresentados em Silva (2008) e Silva e Santos (2011), objetiva-se verificar se os dados de aquisição de vozeamento corroboram a proposta de Mattoso. E há convergência entre a proposta mattoseana e os dados da fala infantil.

Nos contextos de fricativa diante de pausa, esperava-se a realização de [s]. A maior parte das produções atenderam à expectativa; havendo apenas duas realizações de [z] em contexto de ocorrência de [s]. Nos contextos em que a consoante fricativa estava diante de segmentos desvozeados, esperava-se a produção de [s], e todos os dados comprovaram a hipótese. E, em contextos de fricativa antes de segmentos vozeados, o previsto era a realização de [z], mas ocorrem mais produções de [s]. Logo, pode-se perceber que os dados sobre a aquisição de vozeamento corroboram a proposta de Câmara Jr, por mostrarem que a criança não tem nenhuma dificuldade com segmentos surdos, e sim com os elementos sonoros, o que justifica a opção, na estrutura subjacente, pela fricativa alveolar surda.

Por fim, em mais uma exemplificação de como a aquisição de regras da L1 interfere na aquisição de padrões em L2, a pesquisadora retoma, também como base nos trabalhos de Fragozo (2017) e Santos e Fragozo (no prelo), a aquisição da regra de vozeamento progressivo em inglês por falantes de português como L1. Os dados revelam que os sujeitos não adquirem a regra do inglês, de assimilação de progressiva do traço de sonoridade, e aplicam a regra de assimilação regressiva adquirida em português.

As conclusões a que chegam à pesquisadora são muito importantes para a compreensão de como se dá a aquisição da Fonologia do português. Os resultados são claros e consistentes ao revelarem que i) parâmetros podem não ter uma marcação default (o que se observou, por exemplo, nos dados de aquisição de acento primário); ii) as regras fonológicas são adquiridas e a aquisição dessas regras é independente da aquisição da posição dos segmentos (propriedades verificadas nos dados de aquisição dos processos de elisão/ditongação em fronteira vocabular); e iii) resultados divergentes podem ser explicados por divergências na aquisição dos diferentes componentes fonológicos (princípio também verificado na aquisição das regras de sândi vocálico externo).

Os dados apresentados na conferência trazem reflexões pertinentes para a compreensão de aspectos da aquisição da Fonologia do português como L1 e também são de extrema utilidade para a descrição de fenômenos que ocorrem na aquisição de L2 e situações de contato entre línguas.

\section{REFERÊNCIAS}

ADQUIRINDO a Fonologia do Português Brasileiro. Conferência apresentada por Raquel Santana Santos [s.l; s.n]. 2020.1 vídeo (1h34m47s). Publicada no canal da Associação Brasileira de Linguística. Disponível em https://www.youtube.com/watch?v=NDC1uyGAkFc. Acesso em 03 jul 2020.

BISOL, Leda. O ditongo na perspectiva da fonologia atual. D.E.L.T.A, São Pulo, número 5, volume 2, p. 185-224, 1989. 


\section{REVISTA DA ABRALIN}

CHOMSKY, Noam. Aspects of the Theory of Syntax. Cambridge, Massachusetts, the MIT Press, 1965.

CHOMSKY, Noam. Lectures on Government and Binding. Dordrecht: Foris, 1981.

DRESCHER, B. Elan; KAYE, Jonathan D. A computational learning model for metrical phonology. Cognition, volume 34, issue 2, p. 137-195, 1990. https://doi.org/10.1016/0010-0277(90)90042-I

FIKKERT, Paula. On the acquisition of prosodic structure. Dordrecht: ICG, 1994.

FRAGOZO, Carina Silva. Aquisição de regras fonológicas do Inglês por falantes do Português Brasileiro. 2017. Tese (Doutorado em Letras) - Faculdade de Filosofia e Ciências Humanas e Sociais da Universidade de São Paulo, São Paulo, 2017.

SANTOS, Raquel Santana. O acento e a aquisição da linguagem em português brasileiro". In: ARAÚJO, Gabriel Antunes. (Org.). O acento em português: abordagens fonológicas. São Paulo: Parábola, 2007, p. 225-258.

SANTOS, Raquel Santana; FIKKERT, Paula. The use of cues to word stress in word recognition by Brazilian Portuguese and Dutch children. In: GONÇALVES, Giovana Ferreira; DE PAULA, Miriam Rose Brum; SOARES, Marcia Kerske. (org). Estudos em Aquisição Fonológica. 1ed. Pelotas: Editora e Gráfica Universitária, 2011, v. 3, p. 107-132.

SILVA, Cristiane Conceição. Aquisição da regra de assimilação do vozeamento em português brasileiro. 2008. Dissertação (Mestrado em Letras) - Faculdade de Filosofia e Ciências Humanas e Sociais da Universidade de São Paulo, São Paulo 2008.

SILVA, Cristiane Conceição; SANTOS, Raquel Santana. Acquisition of voice assimilation in Brazilian Portuguese. In: COSTA, J.; CASTRO, A.; LOBO, M.; PRATAS, F. (Eds.) Language acquisition and development: proceedings of GALA 2009. Newcastle: Cambridge Scholars Publishing, v. 1, p. 407-418. 2010. 